\title{
A Alegria do Evangelho e os conflitos morais
}

Luís Corrêa Lima ${ }^{1}$

O papa Francisco escreveu uma bela carta sobre a evangelização: a Exortação Apostólica Evangelii Gaudium (EG), cujo título quer dizer: a alegria do Evangelho. Ela traz luzes preciosas a diversos campos, inclusive aos dilemas e conflitos contemporâneos vividos no campo da sexualidade e da família.

De certo modo, esta Exortação já estava presente ainda em germe na intervenção do então cardeal Bergoglio, arcebispo de Buenos Aires, na Congregação dos Cardeais que precedeu o último conclave. Nesta ocasião, ele dizia que evangelizar supõe na Igreja a coragem de sair de si mesma para ir às periferias, não só geográficas mas 'existenciais': ao encontro dos pobres e dos que sofrem com as diversas formas de injustiças, conflitos e carências. Quando a Igreja não sai de si mesma torna-se autorreferencial, ensimesmada, e então adoece. Ela dá lugar a um grave mal que é a mundanidade espiritual: o viver para dar-se glória uns aos outros. $O$ próximo papa, concluía Bergoglio, deve ser um homem que, a partir da contemplação e da adoração de Jesus Cristo, ajude a Igreja a sair de si para as periferias existenciais, que ajude a Igreja a ser a mãe fecunda vivendo da 'doce e confortadora alegria de evangelizar' (BERGOGLIO, 2013).

\section{Os rumos do papa Francisco}

As ideias desta intervenção têm se manifestado fortemente no pontificado de Francisco, e se encontram na sua Exortação, inclusive o título, que vem de uma frase da Exortação de Paulo VI Evangelii Nuntiandi, sobre a evangelização.

Algo muito forte na pregação de Francisco é a contundente refutação do moralismo presente na lgreja. Convém recordar uma declaração de Bento XVI, em 2006, afirmando que o cristianismo não é um conjunto de proibições, mas uma opção positiva. Ele ainda acrescentou que é muito importante evidenciar isso novamente, porque essa consciência hoje quase desapareceu completamente (BENTO XVI, 2006). É muito bom que um Papa tenha reconhecido isto, pois há no cristianismo uma tradição multissecular de insistência na proibição, no pecado, na culpa, na condenação e no medo. A historiografia fala de uma 'pastoral do medo', que com veemência culpabiliza as pessoas e as ameaça de condenação eterna para obter a sua conversão (DELUMEAU, 2003). Isto não se restringe ao passado.

Também hoje, em diversas igrejas e ambientes cristãos, muitos interpretam a doutrina de maneira extremamente restritiva e condenatória, com obsessão pelo pecado. As proibições ligadas à mensagem cristã frequentemente repercutem mais do que o seu conteúdo positivo,

\footnotetext{
${ }^{1}$ Padre jesuíta, doutor em história e professor da PUC-Rio. Este artigo é uma versão revista e ampliada do capítulo: "Evangelii Gaudium: contribuições para as questões contemporâneas" (LIMA, 2014, p.245-250).
} 
tanto dentro da lgreja, entre os fiéis, quanto fora, entre os que a criticam. Há um foco excessivo na proibição. É fundamental buscar na mensagem cristã o seu componente positivo, para que ela seja Boa Nova, Evangelho.

Embora Bento XVI tenha percebido e alertado para este problema, quem realmente 0 enfrenta sistematicamente é seu sucessor Francisco. Já antes da EG, ele dizia que a novidade trazida por Deus à nossa vida é o que de fato nos realiza e nos dá a verdadeira alegria e serenidade, porque Deus nos ama e quer apenas o nosso bem. E também: "o anúncio do amor salvífico de Deus precede a obrigação moral e religiosa. Hoje, por vezes, parece que prevalece a ordem inversa". Uma pastoral missionária não está obcecada pela transmissão desarticulada de uma multiplicidade de doutrinas a se impor insistentemente. $\mathrm{O}$ anúncio deve concentrar-se no essencial, que é também o que mais apaixona e atrai, procurando curar todo tipo de ferida e aquecer o coração, como o dos discípulos de Emaús. A proposta evangélica deve ser mais simples, profunda, irradiante. É desta proposta que vêm depois as consequências morais.

Nesta perspectiva, o confessionário não é uma sala de tortura, mas lugar de misericórdia, no qual o Senhor nos estimula a fazer o melhor que pudermos. Francisco também defende as mães solteiras que querem batizar seus filhos, e enfrentam a 'alfândega pastoral' criada por religiosos rigoristas.

O papa afirmou que o conhecimento da verdade é progressivo. A compreensão do homem muda com o tempo, e sua consciência se aprofunda. Recorde-se o tempo em que a escravatura era aceita e a pena de morte era admitida sem nenhum problema. Os exegetas e os teólogos, como também as outras ciências e a sua evolução, ajudam a Igreja a amadurecer o próprio juízo. Como consequência, há normas e preceitos eclesiais secundários que em outros tempos foram eficazes, mas que hoje perderam valor ou significado. Uma visão da doutrina da Igreja como um bloco monolítico a ser defendido sem matizes é errada (FRANCISCO, 2013b).

\section{Uma Exortação oportuna}

$\mathrm{Na}$ Evangelii Gaudium, estas ideias foram incorporadas de maneira mais articulada, formando um todo mais abrangente. A salvação também tem uma dimensão imanente, pois evangelizar é tornar o Reino Deus presente neste mundo. Os que se deixam salvar por Cristo são libertados do pecado, da tristeza, do vazio interior e do isolamento (EG 1). O Evangelho convida, antes de tudo, a responder a Deus que nos ama e salva, reconhecendo-O nos outros e saindo de nós mesmos para procurar o bem de todos. Todas as virtudes estão a serviço desta resposta de amor. A pregação moral cristã não é uma ética estóica, do cumprimento impassível do dever, e nem um catálogo de pecados e erros. Ela é mais do que uma ascese, exercício em vista do aperfeiçoamento espiritual, e mais do que uma filosofia prática (EG 39). Há uma desproporção a ser evitada quando se fala mais da lei que da graça, mais da lgreja que de Jesus Cristo, mais do papa que da Palavra de Deus (EG 38). 
Isto significa que a graça é mais importante do que a lei. O dom de Deus que cria e redime vem antes de qualquer obrigação humana. Cristo é mais importante do que a Igreja. Esta instituição não é um fim em si mesma. A razão de ser da lgreja é conduzir os povos a Cristo e ajudá-los a viverem n'Ele. A Palavra de Deus é mais importante do que o papa e do que os bispos. Estes exercem na Igreja o ofício autorizado de ensinar, o magistério. Mas este ofício não está acima da Palavra de Deus. Está ao seu serviço, como afirma o Concílio Vaticano II (Dei Verbum, 10)

Francisco também retoma o ensinamento do Concílio sobre a ordem ou hierarquia de verdades na doutrina católica, segundo o nexo delas com o fundamento da fé cristã (Unitatis Redintegratio, 11). Alguns pontos são mais importantes porque estão estreitamente ligados a este fundamento. Outros, por sua vez, são menos importantes porque estão menos ligados a ele. Isto é válido, diz o papa, tanto para os dogmas de fé como para os demais ensinamentos da Igreja, incluindo a doutrina moral. Na mensagem moral da Igreja, há uma hierarquia nas virtudes e ações. As obras de amor ao próximo são a manifestação externa mais perfeita da graça interior do Espírito. A misericórdia é a maior de todas as virtudes (EG 36-37). Os preceitos dados por Cristo e pelos Apóstolos ao povo de Deus são pouquíssimos. E os preceitos adicionados posteriormente pela lgreja devem ser exigidos com moderação, para não tornar pesada a vida aos fiéis e nem transformar a religião numa escravidão (EG 43).

Nesta moral matizada, que o papa expõe, tem grande importância o bem possível. Sem diminuir o valor do ideal evangélico, é preciso acompanhar, com misericórdia e paciência, as possíveis etapas de crescimento das pessoas, que vão se construindo dia a dia. Um pequeno passo no meio de grandes limitações humanas pode ser mais agradável a Deus do que uma vida externamente correta, de quem não enfrenta maiores dificuldades. A consolação e a força do amor salvador de Deus devem chegar a todos. Deus opera misteriosamente em cada pessoa, para além dos seus defeitos e das suas quedas. Um coração missionário não renuncia ao bem possível, ainda que corra o risco de sujar-se com a lama da estrada (EG 44-45).

A Igreja é chamada a ser sempre a casa aberta do Pai, onde há lugar para todos que enfrentam fadigas em suas vidas. Todos podem participar da vida eclesial e fazer parte da comunidade. As portas dos sacramentos não devem se fechar por qualquer razão, a começar pelo primeiro: o batismo A Eucaristia, plenitude da vida sacramental, não é um prêmio para os perfeitos, mas um remédio generoso e um alimento para os que necessitam. Isto tem consequências pastorais a serem consideradas com prudência e audácia. Muitas vezes agimos como controladores da graça e não como facilitadores. Mas a lgreja não é uma alfândega, é a casa paterna (EG 47).

Um exemplo da relação entre o ideal evangélico e o bem possível é a família que tem por base a união exclusiva e indissolúvel entre um homem e uma mulher. Todos os papas defendem esta instituição. Mas certa vez Francisco fez um interessante elogio à mulher paraguaia, que ele considera 'a mais gloriosa da América Latina'. Isto porque, após a Guerra do Paraguai (1864- 
1870), sobraram oito mulheres para cada homem, e essas mulheres fizeram uma escolha difícil e arriscada: ter filhos para salvar a pátria, a cultura, a fé e a língua (FRANCISCO, 2013a). O papa elogia nada menos do que uma prática extramatrimonial de fecundação, hoje chamada produção independente. Uma prática que foi feita em escala nacional em uma circunstância extrema. Estas mulheres são mais gloriosas do que todas as outras, incluindo as que vivem no modelo tradicional de família.

Com isto, Francisco não contraria a moral católica e nem o apreço pelo matrimônio, mas mostra corajosamente o amplo alcance do caminho gradual na aplicação da lei moral. Há uma lei da gradualidade, já apresentada por João Paulo II. Mas ela não é de fato conhecida e deveria ser ensinada de forma mais ampla, como afirmam os bispos franceses em resposta ao questionário preparatório do Sínodo sobre a Família (CEF, 2014).

Este questionário de 39 perguntas foi enviado a todas as dioceses católicas do mundo, com interrogações relevantes e cruciais sobre a lgreja diante das novas situações familiares contemporâneas. A mensagem cristã no campo da sexualidade e da família tem uma grandeza e uma beleza inegáveis, mas também problemas e questionamentos inevitáveis a serem enfrentados. Os ensinamentos da EG podem contribuir muito para uma solução pastoral abrangente e satisfatória. Isto hoje é urgente.

Entre as perguntas, encontram-se: que atenção pastoral se pode dar às pessoas que escolheram viver em uniões do mesmo sexo? E caso adotem crianças, o que fazer para lhes transmitir a fé? A EG não ignora estas questões, mas de maneira discreta aponta caminhos. Em nota de rodapé ( $\mathrm{n}-60$ ) menciona um pronunciamento os bispos da França: "Estender o matrimônio às pessoas do mesmo sexo? Abramos o debate!". É a resposta do episcopado francês ao Projeto de Lei Matrimônio para Todos, que equipara totalmente a união homossexual à união heterossexual.

Os bispos reafirmam a doutrina da Igreja sobre este tema, opondo-se ao Projeto. Mas não só. Eles repudiam a homofobia, e felicitam a evolução do direito que hoje condena toda discriminação e incitação ao ódio em razão da orientação sexual. Reconhecem que muitas vezes não é fácil para a pessoa homossexual assumir sua condição, pois os preconceitos são duradouros e as mentalidades só mudam lentamente, inclusive nas comunidades e nas famílias católicas. Estas são chamadas a acolher toda a pessoa como filho de Deus, qualquer que seja sua situação. Numa união durável entre pessoas do mesmo sexo, para além do aspecto meramente sexual, a Igreja estima o valor da solidariedade, da ligação sincera, da atenção e do cuidado com o outro (CEF, 2012).

Outra importante nota de rodapé da EG (n-59) cita um documento dos bispos norteamericanos: "Ministério junto a pessoas com inclinação homossexual: diretrizes para a assistência pastoral". Segundo os bispos, os que trabalham pastoralmente neste campo são convidados a ouvir as experiências, as necessidades e as esperanças das pessoas homossexuais. Assim se manifesta o respeito à dignidade inata e à consciência do outro. Os 
bispos não aprovam a adoção de crianças por casais do mesmo sexo. No entanto aceitam o batismo de crianças sob a responsabilidade destes casais, se houver o propósito de que elas sejam educadas na fé da Igreja Católica (USCCB, 2006).

Com estas duas notas, a Exortação do papa abre caminho para se responder a questões atuais que são complexas e conflitivas. Não se deve desqualificar previamente as vivências e as aspirações de pessoas homossexuais, como se fossem deploráveis, e lhes despejar condenações morais. E nem se deve utilizar a doutrina como um manual de instruções de um eletrodoméstico, com normas fixas, detalhadas e implacáveis. É fundamental se estabelecer um diálogo fecundo, atento à situação e às circunstâncias do outro, bem como aos matizes do ensinamento da Igreja, em vista do crescimento humano e espiritual.

O ideal de uma Igreja missionária, não ensimesmada, que vai às periferias existenciais, está bem descrita neste trecho da Exortação que convém transcrever na íntegra:

Prefiro uma Igreja acidentada, ferida e enlameada por ter saído pelas estradas, a uma Igreja enferma pelo fechamento e a comodidade de se agarrar às próprias seguranças. Não quero uma Igreja preocupada com ser o centro, e que acaba presa num emaranhado de obsessões e procedimentos. Se alguma coisa nos deve santamente inquietar e preocupar a nossa consciência é que haja tantos irmãos nossos que vivem sem a força, a luz e a consolação da amizade com Jesus Cristo, sem uma comunidade de fé que os acolha, sem um horizonte de sentido e de vida. Mais do que o temor de falhar, espero que nos mova o medo de nos encerrarmos nas estruturas que nos dão uma falsa proteção, nas normas que nos transformam em juízes implacáveis, nos hábitos em que nos sentimos tranquilos, enquanto lá fora há uma multidão faminta e Jesus repete-nos sem cessar: 'Dai-Ihes vós mesmos de comer' (Mc 6, 37) [EG 49].

\section{A família e seus desafios pastorais}

Felizmente, há iniciativas importantes em nível local e regional em favor da abertura ao outro e da acolhida. Com relação às novas situações familiares, a CNBB traz uma proposta renovadora às paróquias. Reconhece que nelas participam pessoas unidas sem o vínculo sacramental e outras em segunda união. Há também as que vivem sozinhas sustentando os filhos, avós que criam netos, tios que sustentam sobrinhos. Há crianças adotadas por pessoas solteiras ou do mesmo sexo, que vivem em união estável. A Igreja, que é família de Cristo, precisa acolher com amor todos os seus filhos. Conservando o ensinamento cristão sobre a família, é necessário usar de misericórdia. Constata-se que muitos se afastaram e continuam se afastando das comunidades porque se sentiram rejeitados, porque a primeira orientação que receberam consistia em proibições e não em viver a fé em meio à dificuldade. Na renovação paroquial, deve haver conversão pastoral para não se esvaziar a Boa-Nova anunciada pela lgreja e, ao mesmo tempo, não deixar de se atender às novas situações da vida familiar. "Acolher, orientar e incluir" nas comunidades os que vivem em outras configurações familiares, são desafios inadiáveis (CNBB, 2014, n217-218).

Ora, a Exortação do papa contém elementos valiosos para acolher, orientar e incluir estas pessoas. Elas podem se beneficiar muito de uma comunidade de fé que as acolha, e 
experimentar com mais intensidade a força, a luz e a consolação da amizade com Jesus Cristo, com um horizonte mais amplo de sentido e de vida. E também têm muito a contribuir, com a sua vida e com os seus dons. Não são só elas que se beneficiam; os outros fiéis também, com sua riqueza humana e espiritual. A diversidade de situações e experiências humanas, incluindo a vivência de outras configurações familiares, muito contribui para se vencer preconceitos e se alcançar a fraternidade dos filhos de Deus. Na diversidade de situações humanas em que se busca o bem, o Espírito de Deus age. Em Buenos Aires, o então cardeal Bergoglio trabalhou com os imigrantes paraguaios, conheceu a história heroica das mulheres paraguaia na época da guerra, e as considerou as mais gloriosas da América Latina. Assim como se pode aprender com estas mulheres, pode-se aprender com tantos outros.

A Igreja Católica vive um momento rico e criativo com a preparação do Sínodo dos Bispos sobre a Família, a se realizar em outubro de 2015. A sua convocação foi feita em 2013, com um documento preparatório contendo perguntas sabiamente instigantes. Em 2014, realizou-se a Assembleia Extraordinária do Sínodo, que debateu as respostas e fez encaminhamentos em vista da Assembleia Ordinária, no próximo ano. Os debates, as entrevistas e os relatórios produzidos tiveram uma notável repercussão na mídia. Mas convém frisar que o sínodo é uma instituição consultiva, bem como os seus relatórios e proposições. Só é ensinamento oficial da Igreja a exortação pós-sinodal, escrita pelo papa. A próxima exortação, sobre a família, só deve sair em 2016.

Mesmo sendo apenas consultivo, o sínodo traz indicações preciosas sobre a situação eclesial, os consensos e as divergências existentes entre os bispos, que são muito importantes para o discernimento do papa. Os relatórios produzidos desde a convocação deste Sínodo apontam claramente nesta direção: não mudar a doutrina e o ideal sobre a família, mas acolher

sem condenar as pessoas que vivem em outras configurações familiares. É muito provável que a exortação pós-sinodal vá estar na linha do papa Francisco, estimulando a flexibilidade e o acolhimento.

O valor deste processo, mais do que os textos, é o debate aberto na lgreja como nunca se viu nas últimas décadas. É muito bom o superior geral dos jesuítas dizer publicamente que pode haver mais amor cristão em uma união irregular do que em um casal casado na Igreja (NICOLÁS, 2014). Ou um arcebispo nigeriano opor-se à criminalização da homossexualidade em seu país, e apoiar famílias que acolhem seus filhos gays com os respectivos companheiros (KAIGAMA, 2014). No contexto africano, tais afirmações são bastante progressistas e ousadas. Tudo isto ajuda a formar na Igreja uma opinião pública que aceita e estima a diversidade sexual.

\section{O alerta e a esperança}

A Exortação Evangelii Gaudium recorda oportunamente o papa João XXIII, canonizado por Francisco, e o seu discurso de abertura do Concílio Vaticano II. Naquela ocasião, João XXIII fez um alerta enérgico contra os profetas da desgraça, que nos tempos atuais só veem 
prevaricação e ruína, sempre anunciando acontecimentos infelizes, como se o fim do mundo fosse iminente. Ao contrário disso, asseverava o papa, na ordem presente das coisas, a Providência divina na sua misericórdia nos eleva para uma ordem de relações humanas que, por obra dos homens e a muitas vezes para além do que eles esperam, se encaminha para o cumprimento dos inesperados e superiores desígnios divinos. E tudo, mesmo as adversidades humanas, converge para o bem da Igreja (JOÃO XXIII, 1962).

Não faltam hoje profetas da desgraça, que veem nas novas configurações familiares o fim da família e da civilização. Para eles, tudo é ameaça. Só resta à lgreja reiterar dogmas, preceitos e proibições, condenando com veemência todos os que vivem nestas situações ou pensam diferente. Ao contrário deles, o papa Francisco afirma que o olhar de quem crê é capaz de reconhecer a luz do Espírito Santo sempre irradiando no meio da escuridão. A nossa fé é desafiada a entrever o vinho em que a água pode ser transformada, e a descobrir o trigo que cresce no meio do joio (EG 84).

Que nunca nos falta esta fé corajosa, de Francisco e de João XXIII.

\section{Para refletir:}

- Qual é a diferença entre moralismo e evangelização?

- Quais são os desafios da sexualidade e da família hoje?

\section{Bibliografia:}

DELUMEAU, Jean. $O$ pecado e o medo: a culpabilização no ocidente (séculos 13-18). 2 vols. Bauru: EDUSC, 2003.

BENTO XVI. "Entrevista de Bento XVI em previsão de sua viagem à Baviera (I)". Boletim eletrônico Zenit, 16 ago. 2006. Disponível em: 〈www.zenit.org>. Acesso em: 31 ago. 2006.

BERGOGLIO, J. M. "Esta é a intervenção magistral do cardeal Bergoglio no pré-conclave". Boletim eletrônico IHU, 27 mar. 2013. Disponível em: <www.ihu.unisinos.br>. Acesso em: 28 mar. 2013.

CEF (CONFÉRENCE DES ÉVÊQUES DE FRANCE). Elargir le mariage aux personnes de même sexe? Ouvrons le débat! Paris, 2012. Disponível em: <www.eglise.catholique.fr〉. Acesso em: 12 mar. 2014.

. Les défis pastoraux de la famille dans le contexte de l'évangélisation. Paris, 2014. Disponível em: 〈www.eglise.catholique.fr〉. Acesso em: 12 mar. 2014.

CNBB (Conferência Nacional dos Bispos do Brasil). Comunidade de comunidades: uma nova paróquia. Brasília, Edições CNBB, 2014.

CONCÍLIO VATICANO II. Decreto unitatis redintegratio sobre o ecumenismo. Roma, 1964. Disponível em: <www.vatican.va>. Acesso em: 19 nov. 2014. 
Constituição dogmática dei verbum sobre a revelação divina. Roma, 1965. Disponível em: <www.vatican.va>. Acesso em: 19 nov. 2014.

FRANCISCO. "Encontro do santo padre com os jornalistas durante o vôo de regresso". 28 jul. Disponível em: <www.vatican.va>. Acesso em: 31 jul. 2013.

. "Entrevista exclusiva do papa Francisco às revistas dos jesuítas". Brotéria, 19 ago. 2013. Disponível em: < www.broteria.pt>. Acesso em 30 set. 2013.

. Exortação apostólica evangelii gaudium (EG). 24 nov. 2013. Disponível em: <w2.vatican.va>. Acesso em: 17 nov. 2014.

JOÃO XXIII. Discurso de sua santidade papa João XXIII na abertura solene do SS. Concílio. Roma, 11 out. 1962. Disponível em: <www.vatican.va>. Acesso em: 12 mar. 2014.

KAIGAMA, I. "Arcebispo nigeriano sai em defesa dos gays e critica os esforços ocidentais para limitar o crescimento da população". Boletim eletrônico IHU, 8 out. 2014. Disponível em: <www.ihu.unisinos.br>. Acesso em: 20 nov. 2014.

LIMA, L. C. "Evangelii Gaudium: contribuições para as questões contemporâneas". In: AMADO, J. P.; FERNANDES, L. A. (orgs.); Evangelii Gaudium em questão: aspectos bíblicos, teológicos e pastorais. São Paulo: Paulinas; Rio de Janeiro: PUC-Rio, 2014, p.245-250.

NICOLÁS, A. "'Pode haver mais amor cristão em uma união irregular do que em um casal casado pela Igreja'. Entrevista com Adolfo Nicolás". Boletim eletrônico IHU, 8 out. 2014. Disponível em: <www.ihu.unisinos.br>. Acesso em: 20 nov. 2014.

USCCB (United States Conference of Catholic Bishops). Ministry to persons with a homosexual inclination: guidelines for pastoral care. Washington, DC, 2006. Disponível em: <www.usccb.org>. Acesso em: 12 mar. 2014. 